\section{Check for updates}

Cite this: Chem. Sci., 2019, 10, 7937

๑ All publication charges for this article have been paid for by the Royal Society of Chemistry

\title{
Low-valent homobimetallic Rh complexes: influence of ligands on the structure and the intramolecular reactivity of $\mathrm{Rh}-\mathrm{H}$ intermediates $\uparrow$
}

\author{
Pascal Jurt, a Oleg G. Salnikov, ${ }^{\text {bc }}$ Thomas L. Gianetti, (D)*ad Nikita V. Chukanov, ${ }^{\text {bc }}$ \\ Matthew G. Baker, ${ }^{a}$ Grégoire Le Corre, ${ }^{a}$ Jaap E. Borger, ${ }^{a}$ Rene Verel, (D) ${ }^{a}$ \\ Sébastien Gauthier, ${ }^{e}$ Olaf Fuhr, (D) Kirill V. Kovtunov, (D) ${ }^{\text {bc }}$ Alexey Fedorov, (D) af \\ Dieter Fenske, ${ }^{\mathrm{g}}$ Igor V. Koptyug (D) ${ }^{\text {bc }}$ and Hansjörg Grützmacher (DD *a
}

\begin{abstract}
Supporting two metal binding sites by a tailored polydentate trop-based (trop $=5 \mathrm{H}$-dibenzo[a,d] cyclohepten-5-yl) ligand yields highly unsymmetric homobimetallic rhodium(।) complexes. Their reaction with hydrogen rapidly forms Rh hydrides that undergo an intramolecular semihydrogenation of two $\mathrm{C} \equiv \mathrm{C}$ bonds of the trop ligand. This reaction is chemoselective and converts $\mathrm{C} \equiv \mathrm{C}$ bonds to a bridging carbene and an olefinic ligand in the first and the second semihydrogenation steps, respectively. Stabilization by a bridging diphosphine ligand allows characterization of a Rh hydride species by advanced NMR techniques and may provide insight into possible elementary steps of $\mathrm{H}_{2}$ activation by interfacial sites of heterogeneous $\mathrm{Rh} / \mathrm{C}$ catalysts.
\end{abstract}

Received 2nd June 2019

Accepted 5th July 2019

DOI: $10.1039 / c 9 s c 02683 e$

rsc.li/chemical-science

fall into two groups: (i) heterobimetallic early-late transition

\section{Introduction}

Bimetallic transition metal complexes have been investigated since the $1970 \mathrm{~s},{ }^{1}$ however despite numerous reports, only a few complexes are widely used in catalytic applications. The most prominent is a rhodium(II) acetate dimer and its derivatives exploited for carbene transfer reactions. ${ }^{2}$ These and more recent bimetallic systems typically outperform monometallic alternatives in terms of activity and selectivity, functional group tolerance, and catalyst loading. ${ }^{3-5}$ The interest in homobimetallic catalysts has recently seen a renaissance. ${ }^{6}$ Selected catalytic applications include diazo-free cyclopropanation, ${ }^{7}$ small molecule activation, ${ }^{8,9}$ hydrogenation, ${ }^{10}$ hydroformylation ${ }^{11}$ and $\mathrm{C}-\mathrm{C}$ coupling reactions. ${ }^{12}$ Notably, heterobimetallic complexes serve as models of the transmetallation step for the latter process. ${ }^{13-17}$ Most of these bimetallic species

\footnotetext{
${ }^{a}$ Department of Chemistry and Applied Biosciences, ETH Zürich, Switzerland. E-mail: hgruetzmacher@ethz.ch

${ }^{b}$ International Tomography Center, SB RAS, Novosibirsk, Russia

'Novosibirsk State University, Novosibirsk, Russia

${ }^{a}$ Department of Chemistry and Biochemistry, University of Arizona, Tucson, USA. E-mail: tgianetti@email.arizona.edu

${ }^{e}$ Université de Rennes, CNRS, ISCR-UMR 6226, F-35000 Rennes, France

${ }^{f}$ Department of Mechanical and Process Engineering, ETH Zürich, Switzerland

${ }^{g}$ Institute of Nanotechnology, Karlsruhe Institute of Technology (KIT), EggensteinLeopoldshafen, Germany

$\dagger$ Electronic supplementary information (ESI) available: experimental spectra and modelling details. CCDC 1919533, 1919534, 1919542, 1919543 and 1919546. For ESI and crystallographic data in CIF or other electronic format see DOI: 10.1039/c9sc02683e
} metal complexes, or (ii) symmetric bimetallic complexes with a core consisting of two mid-to-late transition metals. ${ }^{18}$ Group (i) typically relies on ligands that combine in close proximity both soft and hard moieties, and feature a highly polar dative interaction from the late to the early transition metal. ${ }^{19}$ Group (ii) relies on symmetric bridging ligands, often leading to an apolar bimetallic interaction..$^{20}$ Complexes of the group (ii) have been of particular interest for the understanding of reactivity of small clusters. ${ }^{21-23}$

Rhodium nanoparticles on support materials are widely used in heterogeneous catalysis and various industrial processes especially for hydrogenation-dehydrogenation reactions. ${ }^{24}$ But the mode of interaction between the supported rhodium sites and $\mathrm{H}_{2}$ is not fully understood..$^{25} \mathrm{~A}$ recent DFT study reported that hydrogen activation by small rhodium clusters on a carbon support features a bridging hydride species and a hydride ligand (Scheme 1a) that could be transfered to the carbon support. ${ }^{26}$ However, such intermediates have not been observed experimentally to date. Low valent homobimetallic rhodium complexes serve as molecular models for supported $\mathrm{Rh}$ sites towards understanding the hydrogen activation on such materials. ${ }^{19}$ While representation of supported heterogeneous catalysts by a bimetallic model significantly reduces their complexity, this approach allows for a reliable identification of reaction products and is therefore insightful, despite the apparent oversimplification of the intrinsic complexity of heterogeneous catalysts. That said, examples of well-defined bimetallic $\mathrm{Rh}(\mathrm{I})-\mathrm{Rh}(\mathrm{I})$ systems capable of activating $\mathrm{H}_{2}$ are scarce.$^{27}$ Scheme $1 \mathrm{~b}$ presents a rare dirhodium(I) complex that, 
according to DFT calculations, activates dihydrogen leading to one bridging and one terminal hydride ligand, in a similar fashion as mentioned above for the supported rhodium centers. This mode of the hydrogen activation dissymmetrizes the dirhodium complex while simultaneously forming a stabilizing $\mathrm{Rh}$-Rh bond. ${ }^{28}$ Again, experimental evidence for such a dirhodium dihydride species is still lacking, although dissymmetric complexes with a dirhodium(I) core containing chloride ligands in place of the hydrides were reported. ${ }^{29}$ A symmetric dirhodium dihydride complex, which forms an intermetallic bond, was characterized by NMR and IR (Scheme 1c). ${ }^{30}$

In contrast to the exploitation of complexes with symmetric ligands, the advantages of dissymmetric ligands to control the reactivity of two adjacent $\mathrm{Rh}$ centers are underutilized. ${ }^{31}$ The dissymmetry of the electronic environment imposed by the ligand could not only enable otherwise inaccessible reactivity manifolds, ${ }^{19,32}$ but also allows modelling the environment and complexity of heterogeneous catalysts (metal-support interface, surface defects, etc.). In particular, a non-innocent ligand with multiple unsaturated $\mathrm{C}-\mathrm{C}$ bonds could provide insights in the reactivity of $\mathrm{Rh} / \mathrm{C}$ interfacial sites of metallic $\mathrm{Rh}$ nanoclusters or nanoparticles on carbon-based supports.

Previous work by the Grützmacher group showed that the bidentate concavely shaped tropPPh $\mathrm{P}_{2}(\operatorname{trop}=5 H$-dibenzo $[a, d]$ cyclohepten-5-yl) ligand featuring both a $\sigma$-donor $\left(\mathrm{Ph}_{2} \mathrm{P}\right.$ group) and a $\pi$-accepting binding site $\left(\mathrm{C}=\mathrm{C}_{\text {trop }}\right)$ enables a strong binding $^{.33}$ to several transition metal centers including $\mathrm{Pd}^{\mathbf{3 4}}$ $\mathrm{Rh}^{35,36}$ and $\mathrm{Ir}^{36,37}$ In order to synthesize a homobimetallic low valent dirhodium complex, we developed a tailored (TMS) $\mathrm{C} \equiv \mathrm{C}{ }_{2}{ }_{2}$ tropPPh ${ }_{2}$ ligand with a second binding site created by two alkyne moieties (vide infra). This framework supports a $\mathrm{Rh}_{2}(\mathrm{I})$ complex with labile triflate ligands cis to the polarized intermetallic $\mathrm{Rh}-\mathrm{Rh}$ bond and demonstrates cooperativity of two metal sites in the hydrogen activation. However, resulting hydrides react intra-molecularly by adding hydrogen to the alkyne units of the ${ }^{\{(\mathrm{TMS}) \mathrm{C} \equiv \mathrm{C}\}}{ }_{2}$ tropPPh $_{2}$ ligand. We performed in

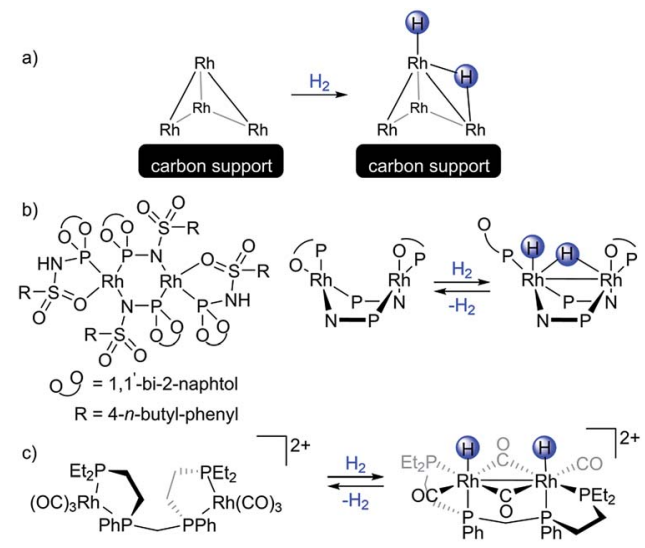

Scheme 1 (a) Hydrogen activation as calculated by DFT for small rhodium clusters on a carbon support. (b) A bimetallic Rh hydrogenation catalyst (left) and its proposed hydrogen activation mode, according to DFT (right). (c) A rare dirhodium(II) dihydride characterized by NMR. depth NMR studies, including the use of the parahydrogeninduced polarization (PHIP) technique, ${ }^{38-42}$ to elucidate the structure and transformations of these Rh hydride intermediates that convert the trop ligand into a carbene-like motif via semihydrogenation of the first $\mathrm{C} \equiv \mathrm{C}$ bond. Remarkably, the semihydrogenation of the second $\mathrm{C} \equiv \mathrm{C}$ bond proceeds with a different chemoselectivity forming a cis-olefinic ligand. Tuning the Rh coordination sphere by exchanging one triflate for a bis(diphenylphosphino)methane (dppm) ligand inhibits the semihydrogenation steps and allows to characterize the intermediate rhodium hydride species by NMR. Overall, reactivity of $\mathrm{Rh}_{2}$ complexes in a carbon-rich ligand environment offers mechanistic insight on the net $\mathrm{H}_{2}$ activation across a $\mathrm{Rh}-$ $\mathrm{Rh}$ bond and interaction of $\mathrm{Rh}-\mathrm{H}$ species with a carbon support in $\mathrm{Rh} / \mathrm{C}$ heterogeneous catalysts.

\section{Results and discussion}

Synthesis and characterization of 10,11-di-(trimethylsilyl) acetylene-5H-dibenzo[ $[a, d]$ cyclohepten-5-diphenylphosphine and its $R_{2}$ complexes

The tropketone $\mathbf{1}^{\mathbf{4 3}}$ was converted to the polydentate trop ligand 5 in four steps with an overall yield of 34\%, utilizing a Sonogashira protocol and conventional functional group transformation reactions (Fig. 1, top panel). Mixing 5 with one equivalent of $\left[\left(\mathrm{C}_{2} \mathrm{H}_{4}\right)_{2} \mathrm{RhCl}\right]_{2}$ leads to the chloro bridged dimer 6 having two adjacent rhodium centers per trop ligand (83\% yield). The abstraction of the chloride ligands in $\mathbf{6}$ with silver triflate gives the monomeric homobimetallic complex 7 in $82 \%$ yield. According to single crystal X-ray diffraction of 7 , two triflate ligands bridge between the two rhodium centers. The addition of one equivalent of diphenylphosphinomethane (dppm) displaces one triflate ligand to form the dppm adduct 8 ( $83 \%$ yield, Fig. 1 , bottom panel).

Complexes 6-8 were characterized by single crystal X-ray diffraction methods. All complexes possess a distorted square planar geometry around Rh1 and a nearly ideal square planar environment around $\mathrm{Rh} 2\left(\tau_{\mathrm{Rh} 1}=0.29,0.46\right.$ and 0.37 , and $\tau_{\mathrm{Rh} 2}=$ 0.06, 0.01 and 0.03 for 6,7 and 8 respectively). ${ }^{44}$ The Rh-Rh contact in monomeric 7 is $2.6297(2) \AA$, that is $0.21 \AA$ shorter than in dimeric 6 (2.8464(3) A, Table 1). This shortening of the $\mathrm{Rh}-\mathrm{Rh}$ distances is accompanied by an elongation of the $\mathrm{P}-\mathrm{Rh}$ bond from 2.1829(3) $\AA$ in the chloro bridged dimer 6 to 2.2115(5) $\AA$ in the monomeric triflate complex 7, indicating that the $\mathrm{Rh}-\mathrm{Rh}$ interaction in 7 is stronger. However, the bond lengths of the coordinated $\mathrm{C}-\mathrm{C}$ multiple bonds as well as the respective $\mathrm{C}-\mathrm{Rh}$ distances do not differ much between 6 and 7 (Table 1). Dppm adduct 8 has a Rh-Rh bond of 2.7691(7) $\AA$, an intermediate value between those of 6 and 7. Additional significant changes are observed in the alkene/alkyne bonds trans to $\mathrm{P} 2$ and $\mathrm{P} 3$, which are elongated in 8 (Rh1-ct(C5-C6) 1.981(7) A and Rh2-ct(C1-C2) 2.232(7) A in 8 compared to Rh1ct(C5-C6) 1.913(2) $\AA$ and Rh2-ct(C1-C2) 2.062(2) $\AA$ in 7), explained by the higher trans influence of the phosphine ligand. ${ }^{45}$

The ${ }^{13} \mathrm{C}$ NMR olefinic chemical shifts for the chloro bridged dimer 6 and the monomeric triflate complex 7 are similar $\left(\delta^{13} \mathrm{C}\right.$ 

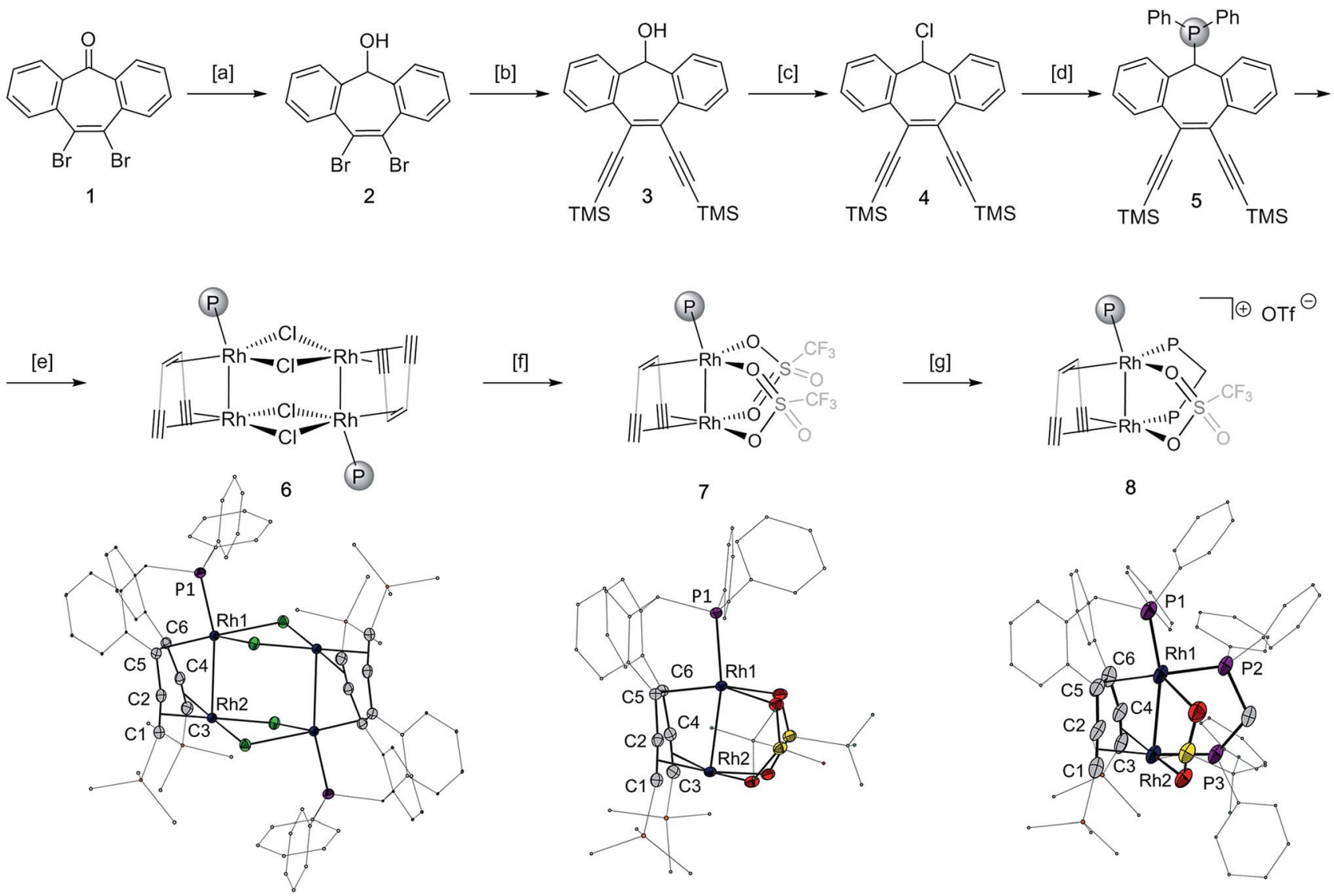
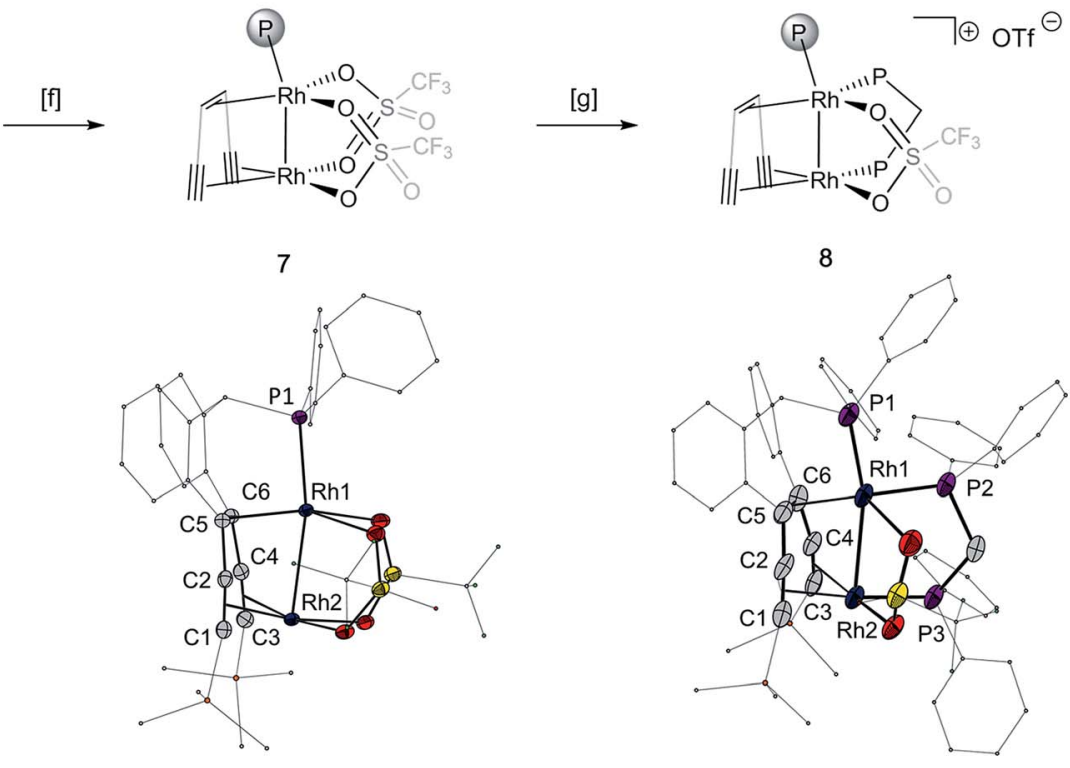

Fig. 1 [a] $\mathrm{NaBH}_{4}, \mathrm{MeOH}, 98 \%$. [b] TMSC $\equiv \mathrm{CH}, 5 \mathrm{~mol} \%\left[\mathrm{Pd}\left(\mathrm{PPh}_{3}\right)_{4}\right.$ ], Cul, toluene, $\mathrm{Et}_{3} \mathrm{~N}, 76 \%$. [c] SOCl$, \mathrm{DCM}, 0{ }^{\circ} \mathrm{C}, 80 \%$. [d] $\mathrm{LiPPh}$, toluene, 63\%. [e] $\left[\left(\mathrm{C}_{2} \mathrm{H}_{4}\right) \mathrm{RhCl}\right]_{2}$, benzene, 82\%. [f] AgOTf, DCM, 83\%. [g] $\mathrm{Ph}_{2} \mathrm{PCH}_{2} \mathrm{PPh}_{2}, \mathrm{DCM} /$ hexane, $80 \%$. The representation of ligand 5 is simplified in structures 6-8 for clarity. The crystal structures of bimetallic complexes $6-8$ are given below the respective chemical structures and have the solvent molecules and non-coordinated triflate anions omitted for clarity.

Table 1 Selected bond lengths $(\AA)$ and angles $\left(^{\circ}\right)$ for complexes 6 to 8 , ct: center of coordinated multiple bond

\begin{tabular}{llll}
\hline Bond length or angle & $\mathbf{6}$ & $\mathbf{7}$ & $\mathbf{8}$ \\
\hline Rh1-Rh2 & $2.8464(3)$ & $2.6297(2)$ & $2.7691(7)$ \\
Rh1-P1 & $2.1829(3)$ & $2.2115(5)$ & $2.2385(17)$ \\
C1-C2 & $1.242(3)$ & $1.246(3)$ & $1.235(10)$ \\
C3-C4 & $1.247(4)$ & $1.248(3)$ & $1.230(9)$ \\
C5-C6 & $1.499(3)$ & $1.495(3)$ & $1.475(10)$ \\
ct(C1-C2)-Rh2 & $2.077(2)$ & $2.062(2)$ & $2.232(7)$ \\
ct(C3-C4)-Rh2 & $2.054(3)$ & $2.057(2)$ & $2.051(6)$ \\
ct(C5-C6)-Rh1 & $1.962(2)$ & $1.913(2)$ & $1.981(7)$ \\
P1-Rh1-Rh2 & $162.708(19)$ & $168.488(16)$ & $164.92(5)$ \\
Rh1-Rh2-ct(C1-C2) & $78.83(7)$ & $87.48(6)$ & $80.82(19)$ \\
Rh1-Rh2-ct(C3-C4) & $81.01(7)$ & $83.07(6)$ & $80.93(19)$ \\
ct(C1-C2)-Rh2-ct(C3-C4) & $89.67(10)$ & $82.19(6)$ & $85.9(2)$ \\
P1-Rh1-ct(C5-C6) & $91.43(7)$ & $90.56(8)$ & $91.4(2)$
\end{tabular}

$=37.9$ vs. 37.0 ppm for 6 and 7, respectively). However, a strong shielding is observed for both triple bonds in the triflate complex $\left(\delta^{13} \mathrm{C}=99.4\right.$ to $86.6 \mathrm{ppm}$ for $\mathrm{TMS}-\mathrm{C} \equiv C$ and $\delta^{13} \mathrm{C}=$ 74.0 to 65.3 for TMS $-C \equiv \mathrm{C}$ for 6 and 7 , respectively) suggesting that Rh2 site in 7 is more electron-rich than in 6 . Likely, the Rh$\mathrm{Rh}$ bond can be best described as a dative bond where electron donation from Rh2 into the antibonding orbital of the Rh1-P bond occurs, similar to the bonding in early-late bimetallic transition metal complexes. ${ }^{19}$ For complex $\mathbf{8}$, this is supported by calculations, as the HOMO-2 and HOMO-3 orbitals show a clear overlap between the two metal centers, with a larger orbital contribution of Rh2 (Fig. S1†).

\section{Reactivity of $\left[\mathrm{Rh}_{2}{ }^{\{(\mathrm{TMS}) \mathrm{C} \equiv \mathrm{C}\}}{ }_{2}\right.$ tropPPh 2$]$ complexes with $\mathrm{H}_{2}$}

Adding hydrogen (1-2 bar) to the headspace of a J. Young NMR tube with monomeric triflate complex 7 dissolved in $\mathrm{CD}_{3} \mathrm{CN}$ and following the reaction progress by NMR allows observing a stepwise hydrogenation of the two triple bonds of the supporting $\{(\mathrm{TMS}) \mathrm{C} \equiv \mathrm{C}\}{ }_{2}$ tropPPh $_{2}$ ligand. The first alkyne semihydrogenation step proceeds quantitatively within $15 \mathrm{~min}$ and, strikingly, yields carbene species 9 (Scheme 2). Such chemoselective hydrogenation is uncommon and was only previously observed for alkynes bound to $\mathrm{d}^{8}$ metal centers with a $\mathrm{Pt}(\mathrm{II})-(\mu$ $\mathrm{H})_{3}-\mathrm{Pt}(\mathrm{II})$ core. ${ }^{46}$ The semihydrogenation of the remaining triple bond leads to a coordinated alkene $\mathbf{1 0}$ (Scheme 2) and proceeds with a slower rate requiring $c a .20 \mathrm{~h}$ at 2 bar of $\mathrm{H}_{2}$ for quantitative conversion. The carbene complex 9 and the carbene alkene complex 10 display characteristic signals in ${ }^{13} \mathrm{C}$ NMR spectra assigned to the bridging carbene at $\delta^{13} \mathrm{C}=171.1$ and 


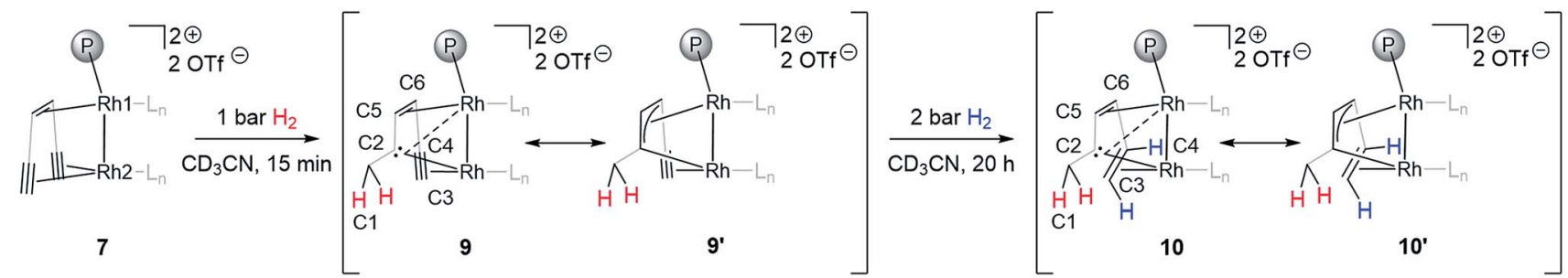

Scheme 2 Stepwise semihydrogenation of 7 in $C D_{3} C N$ at room temperature followed by in situ NMR spectroscopy. $L_{n}$ is $C D_{3} C N$. The representation of ligand 5 (Scheme 1) was simplified for clarity.

166.3 ppm and the methylene carbon at $\delta^{13} \mathrm{C}=35.5$ and $36.7 \mathrm{ppm}$, respectively. The methylene group formed is identified by the two diastereotopic proton signals in the ${ }^{1} \mathrm{H}$ NMR spectrum at $\delta^{1} \mathrm{H}=2.38,3.18$ and 1.99, 3.03 ppm for 9 and 10, respectively, showing a geminal ${ }^{2} J_{\mathrm{HH}}$ coupling of 12.1 and 13.1 Hz. 2D NMR experiments (COSY, HSQC and HMBC) support the structural assignment of complexes 9 and 10; this data is presented in the ESI (Fig. S2-S5†). The bridging nature of the carbene ligand is further characterized by two rather different $J_{\mathrm{CRh}}$ coupling constants for $9\left({ }^{1} J_{\mathrm{CRh}}=33.9,11.1 \mathrm{~Hz}\right)$ and for $10\left({ }^{1} J_{\mathrm{CRh}}=35.7,11.2 \mathrm{~Hz}\right)$, which suggests that the Rh2 center has a closer contact to the carbene carbon than Rh1 (Scheme 2). Results of a single crystal X-ray analysis of $\mathbf{1 0}$ are consistent with the proposed structure, although the quality of data for 10 is rather poor (Fig. S6 $\dagger$ ). The observed ${ }^{1} J_{\mathrm{CRh}}$ coupling constants of 33.9 and $35.7 \mathrm{~Hz}$ are similar to the earlier reported values for dinuclear rhodium(I) complexes with bridging carbenes which likewise show ${ }^{1} J_{\mathrm{CRh}}$ in the range of $30-32 \mathrm{~Hz} .{ }^{6}$ The assignment of cis-semihydrogenation in $\mathbf{1 0}$ is supported by two ${ }^{1} \mathrm{H}$ NMR signals at $\delta^{1} \mathrm{H}=2.58$ and $5.07 \mathrm{ppm}$ coupled to each other with ${ }^{3} \mathrm{~J}_{\mathrm{HH}}=11.3 \mathrm{~Hz}$.

The two olefinic carbons of the central trop double bond in 6-8 (C5 and C6 in Fig. 1) are strongly shielded, most likely due to the anisotropic effects of the neighboring alkyne group (the chemical shifts range from $\left.\delta^{13} \mathrm{C}=37.0-48.7 \mathrm{ppm}\right)$. Upon hydrogenation, these carbons show a remarkable difference in the chemical shift (9: $\delta^{13} \mathrm{C}=43.3$ and $98.8 \mathrm{ppm}, 10: \delta^{13} \mathrm{C}=62.9$ and $100.0 \mathrm{ppm}$ for C6 and C5 respectively, see Scheme 2). The chemical shift change in C6 is consistent with hydrogenation of the alkyne to alkene, lowering its anisotropic effect. However, the strong deshielding of $\mathrm{C} 5$ in both complexes indicates an overlap between the $\mathrm{C} 2$ carbene p orbital and the trop double bond, leading to an allyl-like bonding around Rh1. ${ }^{47}$ This inference is further confirmed by the $J_{\mathrm{CRh}}$ coupling constants, which are much smaller for the C5 carbon than for the C6 carbon (Table 2, numbering in the trop ligand is according to Scheme 2). A similar bonding motif was reported with a dinickel(I) core in the solid state. ${ }^{48}$ To summarize, complexes 9 and 10 contain a carbene carbon in conjugation with the central double bond of the trop ligand and this allyl-type ensemble is bridging to the $\mathrm{Rh}(\mathrm{I})-\mathrm{Rh}(\mathrm{I})$ fragment. The ligand sphere of Rh2 in 9 and 10 in solution is likely stabilized by $\mathrm{CD}_{3} \mathrm{CN}$.

Furthermore, a characteristic shielding is observed in the ${ }^{31} \mathrm{P}$ NMR spectra when comparing the trop phosphorus signal at $\delta^{31} \mathrm{P}$ $=104.6 \mathrm{ppm}$ in the monomeric triflate complex 7 with the respective signals at $\delta^{31} \mathrm{P}=59.7$ and $67.0 \mathrm{ppm}$ in the carbene complex 9 and the carbene alkene complex 10. This change is accompanied by a shift to a smaller ${ }^{1} J_{\mathrm{Rh} 1 \mathrm{P}}$ coupling constant in 9 and $10\left({ }^{1} J_{\mathrm{Rh} 1 \mathrm{P}}=127.2\right.$ and $\left.136.0 \mathrm{~Hz}\right)$ as compared to that in 7 $\left({ }^{1} J_{\mathrm{Rh} 1 \mathrm{P}}=185.6 \mathrm{~Hz}\right)$, indicating a higher trans influence of the Rh2 center in $\mathbf{9}$ and $\mathbf{1 0}$ compared to 7. This suggests weakening of the $\mathrm{P}-\mathrm{Rh}$ bond that is offset by strengthening of the $\mathrm{Rh}-\mathrm{Rh}$ bond, attributed to the interaction with the bridging carbene ligand. ${ }^{\mathbf{4 9}}$ The latter could also be viewed as a distorted

Table 2 Selected NMR data of complexes 7, 9, and 10

\begin{tabular}{|c|c|c|c|c|c|c|c|}
\hline Nucleus & Position & $\delta(\mathrm{ppm})$ & $J(\mathrm{~Hz})$ & $\delta(\mathrm{ppm})$ & $J(\mathrm{~Hz})$ & $\delta(\mathrm{ppm})$ & $J(\mathrm{~Hz})$ \\
\hline & $\mathrm{C} 2$ & 97.0 & $J_{\mathrm{CRh}}=7.7$ & 171.1 & $J_{\mathrm{CRh}}=33.9,11.1$ & 166.3 & $J_{\mathrm{CRh}}=35.7,11.2$ \\
\hline & $\mathrm{C} 3$ & 75.4 & $J_{\mathrm{CRh}}=11.9$ & 76.9 & $J_{\mathrm{CRh}}=11.6$ & 57.3 & $J_{\mathrm{CRh}}=15.6$ \\
\hline & $\mathrm{C} 4$ & 97.0 & $J_{\mathrm{CRh}}=7.7$ & 101.7 & $J_{\mathrm{CRh}}=8.1$ & 81.5 & $J_{\mathrm{CRh}}=12.4,2.7$ \\
\hline${ }^{1} \mathrm{H}$ & $\mathrm{C} 1 \mathrm{H}_{2}$ & & & $2.38,3.18$ & ${ }^{2} J_{\mathrm{HH}}=12.1$ & $1.99,3.03$ & ${ }^{2} J_{\mathrm{HH}}=13.1$ \\
\hline${ }^{31} \mathrm{P}$ & & 104.6 & $\begin{aligned}{ }^{1} J_{\mathrm{PRh} 1} & =185.6 \\
{ }^{2} J_{\mathrm{PRh} 2} & =4.6\end{aligned}$ & 59.7 & $\begin{array}{l}{ }^{1} J_{\mathrm{PRh} 1}=127.2 \\
{ }^{2} J_{\mathrm{PRh} 2}=18.4\end{array}$ & 67.0 & $\begin{aligned}{ }^{1} J_{\mathrm{PRh} 1} & =136.0 \\
{ }^{2} J_{\mathrm{PRh} 2} & =7.1\end{aligned}$ \\
\hline${ }^{103} \mathrm{Rh}$ & $\begin{array}{l}\mathrm{P}-R h 1-\mathrm{Rh} 2 \\
\mathrm{P}-\mathrm{Rh} 1-R h 2\end{array}$ & $\begin{array}{l}-6852 \\
-a\end{array}$ & ${ }^{1} J_{\mathrm{Rh} 1 \mathrm{P}}=186$ & $\begin{array}{l}-7184 \\
-6733\end{array}$ & ${ }^{1} J_{\mathrm{Rh} 1 \mathrm{P}}=126$ & $\begin{array}{l}-7163 \\
-7066\end{array}$ & ${ }^{1} J_{\mathrm{Rh} 1 \mathrm{P}}=136$ \\
\hline
\end{tabular}

${ }^{a}$ No proton showed a significant coupling to Rh2 in the ${ }^{1} \mathrm{H}^{-103} \mathrm{Rh}$ HMQC spectrum. 
a)

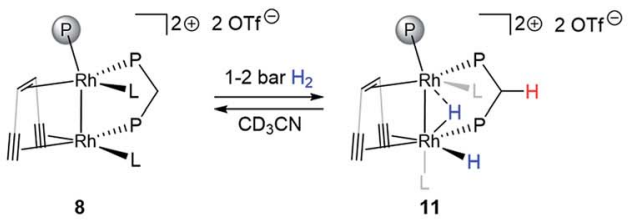

b)

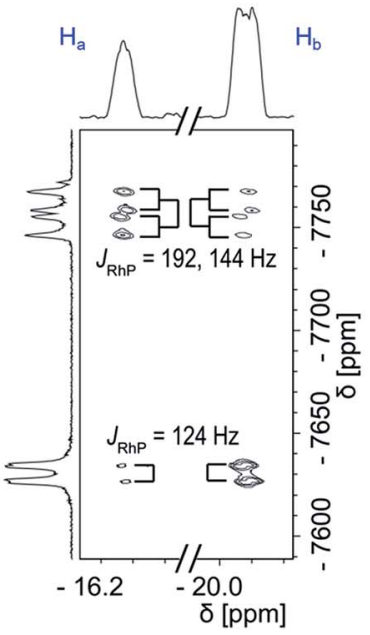

d)

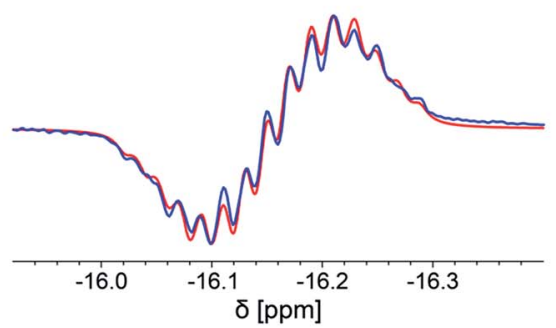

c) $\mathrm{H}_{\mathrm{a}}$

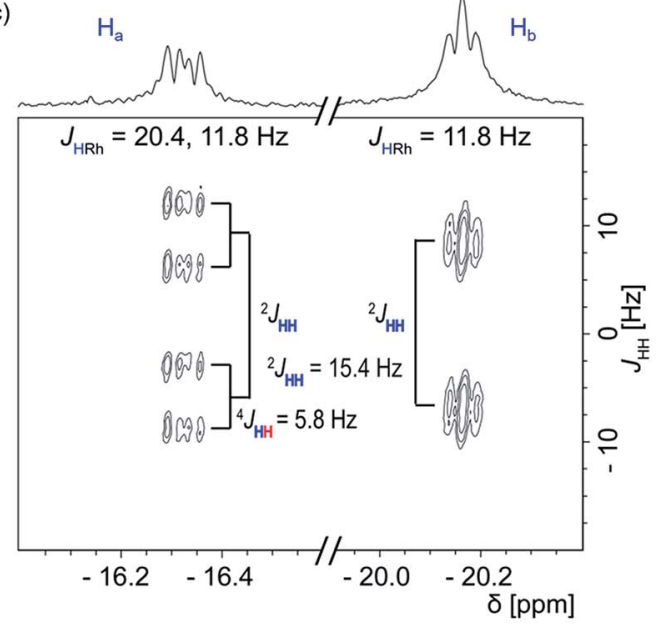

e)

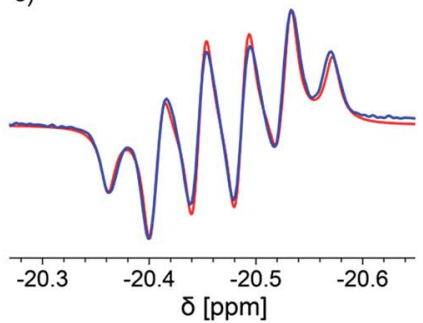

Fig. 2 Proposed activation of hydrogen by complex 8 ( $\mathrm{L}$ is one acetonitrile ligand) and relevant spectroscopic data: (a) reaction of 8 with hydrogen, as proposed on the basis of NMR experiments, (b) J-resolved ${ }^{1} \mathrm{H}\left\{{ }^{31} \mathrm{P}\right\}$ spectrum, (c) ${ }^{1} \mathrm{H}-{ }^{103} \mathrm{Rh} \mathrm{HMQC}$ spectrum, (d) PHIP ${ }^{1} \mathrm{H}$ spectrum (blue) with simulation (red), of hydride $\mathrm{H}_{\mathrm{a}}$ (e) $\left.\mathrm{PHIP}{ }^{1} \mathrm{H}^{31} \mathrm{P}\right\}$ spectrum (blue) with simulation (red) of hydride $\mathrm{H}_{\mathrm{b}}$. The representation of ligand 5 was simplified in structures 8, 11 and 12 for clarity.

dirhodacyclopropane. ${ }^{50}$ Analysis of the ${ }^{103} \mathrm{Rh}$ NMR data reveals that Rh1 is significantly shifted upfield when comparing 7 with 9 and $10\left(\delta^{103} \mathrm{Rh}=-6852,-7184\right.$, and $-7163 \mathrm{ppm}$ for 7,9 and 10, respectively) further supporting a more electron rich $\mathrm{Rh}$ core. Comparing 9 and 10 using the ${ }^{103} \mathrm{Rh}$ NMR shift of Rh2 suggests that the Rh2 site in $\mathbf{1 0}$ is more electron rich than in $\mathbf{9}\left(\delta^{103} \mathrm{Rh}=\right.$ $-6733,-7066 \mathrm{ppm}$ for 9 and 10, respectively), ${ }^{51}$ which is consistent with a change in the ligand sphere from an alkyne to a weaker $\pi$ accepting alkene. These results indicate that the bimetallic core becomes more electron rich with each hydrogenation step.

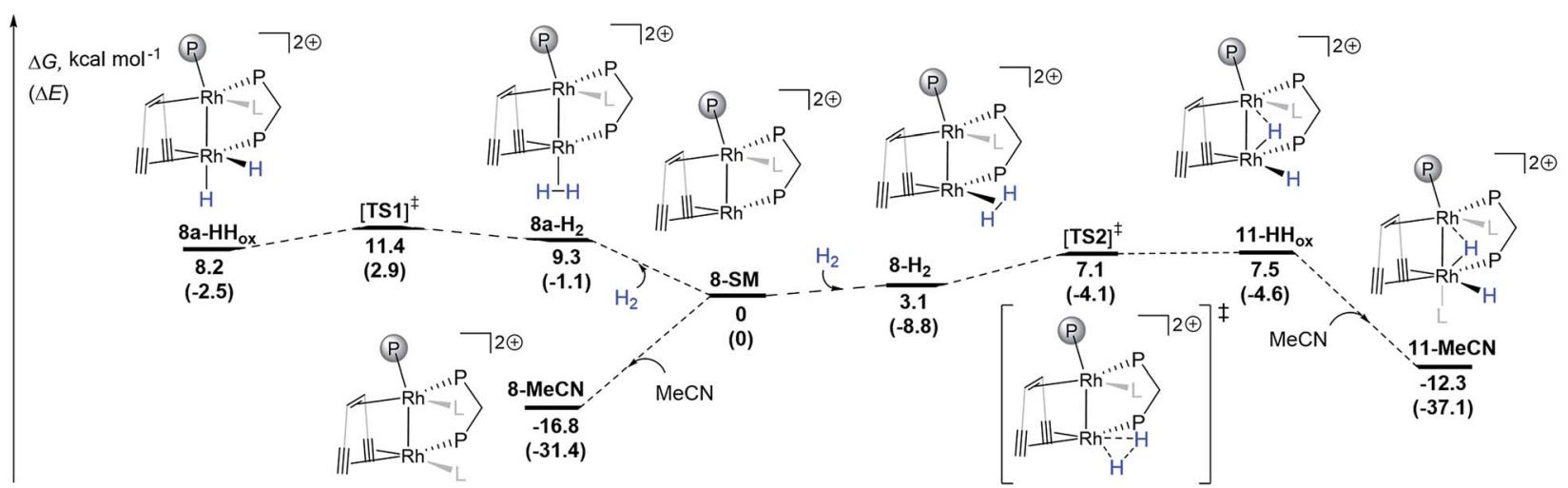

Scheme 3 DFT calculations (Gaussian09, $\omega$ B97X-D/def2-SVP) for the hydrogen activation pathways from $8-\mathrm{SM}_{\text {to }} 8 \mathrm{a}-\mathrm{HH}_{\mathrm{ox}}$ and $11-\mathrm{HH}_{\mathrm{ox}}$. $\mathrm{L}$ is one acetonitrile ligand. The transition states were confirmed to connect the two respective energy minima by IRC calculations (see ESI $\uparrow$ ). 


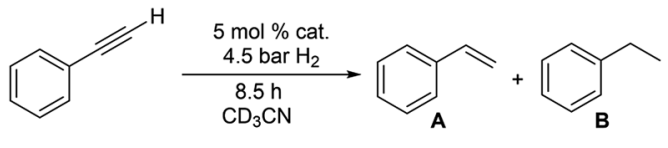

Catalysts:

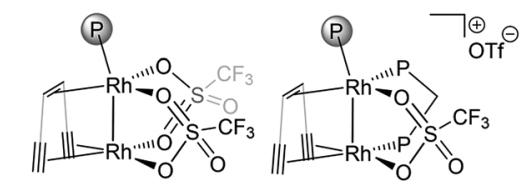

7

8
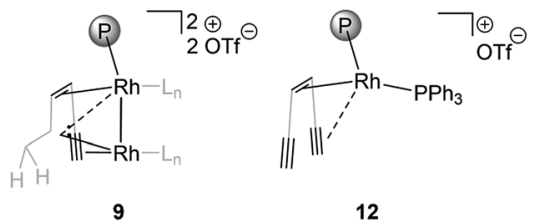

Fig. 3 Catalytic semihydrogenation of phenylacetylene by bimetallic catalysts 7-9 and the benchmark monometallic catalyst $12\left(L_{n}\right.$ is $\mathrm{CD}_{3} \mathrm{CN},{ }^{\{(T M S) C} \equiv{ }_{2}{ }_{2}$ tropPPh $_{2}$ ligand is simplified for clarity).

Table 3 Results of the catalytic semihydrogenation of phenylacetylene. Conversion and selectivities are reported after 8.5 hours of the reaction

\begin{tabular}{|c|c|c|c|c|c|}
\hline Entry & Catalyst & Conv. (\%) & Sel. A (\%) & Sel. B (\%) & $k_{\text {obs }}\left(10^{-2} \mathrm{~h}^{-1}\right)$ \\
\hline 1 & 7 & 39 & 90 & 10 & 5.9 \\
\hline 2 & 8 & 79 & 97 & 3 & 23 \\
\hline 3 & 9 & 39 & 97 & 3 & 6.7 \\
\hline 4 & 12 & 16 & $>99$ & - & 0.95 \\
\hline
\end{tabular}

We have also performed the semihydrogenation of the ligand in a stepwise manner, where the carbene complex $\mathbf{9}$ was formed first under $\mathrm{H}_{2}$, followed by deuteration to the carbene alkene complex 10 under a $D_{2}$ atmosphere. In this case, deuterium is only incorporated at the double bond (blue hydrogens atoms in Scheme 2) indicating irreversible ligand hydrogenation. This observation is consistent with the results of an experiment where $\mathbf{1 0}$ was formed in situ under an atmosphere of $\mathrm{H}_{2}$ and subsequently placed under an atmosphere of $D_{2}$. In this case no deuterium incorporation is observed within $14 \mathrm{~h}$, indicating that both hydrogenation steps are irreversible (Fig. S7 and S8 $\dagger$ ).

To gain further insight on how the $\mathrm{H}_{2}$ molecule is activated at the $\mathrm{Rh}_{2}$ fragment, parahydrogen $\left(p-\mathrm{H}_{2}\right)^{52,53}$ was used instead of $\mathrm{H}_{2}$ for the hydrogenation of monomeric triflate complex 7 , resulting in no detectable hyperpolarized $\mathrm{Rh}$ hydride intermediates. Interestingly, the only PHIP hyperpolarized signals observed in the ${ }^{1} \mathrm{H}$ NMR spectra are assigned to the methylene $\mathrm{CH}_{2}$ protons of carbene complex 9 (Fig. S10 and S11 $\dagger$ ), which establishes a pairwise hydrogen addition to the triple bond of the trop ligand when forming the bridging carbene complex 9 .

Next, we added 1-2 bar of $\mathrm{H}_{2}$ to the solution of dppm adduct 8 in $\mathrm{CD}_{3} \mathrm{CN}$ in a J. Young NMR tube and observed no formation of the bridging carbene-like moiety. Instead, a mixture of $\mathbf{8}$ and a Rh dihydride complex $\mathbf{1 1}$ (Fig. 2a) is formed that is stable for several days at room temperature. Two characteristic hydride signals are observed at approximately $\delta^{1} \mathrm{H}=-16.2$ and $-20.5 \mathrm{ppm}$. Dihydride 11 was further characterized by low temperature NMR experiments as well as using the PHIP technique. The removal of the $\mathrm{H}_{2}$ (or the $D_{2}$ ) atmosphere from a J. Young NMR tube containing a mixture of the dppm adduct 8 and the dihydride $\mathbf{1 1}$ cleanly reforms $\mathbf{8}$, indicating a fully reversible hydrogen activation (Fig. S12 and S13†). This is further supported by EXSY spectroscopy, variable temperature NMR and a partially negative line-shape (PNL) of the orthohydrogen peak in PHIP NMR (Fig. S14-S17†)..$^{38,54,55}$ Since PNL does also occur in PHIP experiments with 7 , the same mode of hydrogen activation is likely occurring with both species, 7 and 8. Upon formation of cis-dihydride 11, the Rh1 NMR resonance $\delta^{103} \mathrm{Rh} 1=-7758 \mathrm{ppm}$ is significantly shifted to lower frequencies. This low-frequency shift exceeds even the ones observed for $\mathbf{9}\left(\delta^{103} \mathrm{Rh} 1=-7184 \mathrm{ppm}\right)$ and $\mathbf{1 0}\left(\delta^{103} \mathrm{Rh} 1=-7163\right.$ $\mathrm{ppm})$. The $\mathrm{Rh} 2$ nucleus $\left(\delta^{103} \mathrm{Rh}=-7630 \mathrm{ppm}\right)$ shows likewise a strong shift to lower frequencies relative to the ${ }^{103} \mathrm{Rh} 2$ nuclei in 9 and $10\left(\delta^{103} \mathrm{Rh} 2=-6733\right.$ and $-7066 \mathrm{ppm}$, respectively $)$, which is in agreement with the influence of strongly $\sigma$ donating hydrides on both metal centers (Fig. 2b). ${ }^{1} \mathrm{H}\left\{{ }^{31} \mathrm{P}\right\}$ J-resolved 2D NMR spectroscopy reveals the $J_{\mathrm{HH}}$ and $J_{\mathrm{HRh}}$ coupling constants (Fig. 2c). The two hydrides remain coupled in complex 11, revealed by the ${ }^{2} J_{\mathrm{HH}}=15.4 \mathrm{~Hz}$ splitting in the indirect dimension. The hydride at $\delta^{1} \mathrm{H}=-16.2 \mathrm{ppm}$ shows an additional ${ }^{4} \mathrm{JH}_{\mathrm{HH}}$ $=5.8 \mathrm{~Hz}$ coupling to another proton, assigned by COSY to one of the methylene protons of the dppm ligand (red in Fig. 2a). The NMR characterization of $\mathbf{1 1}$ was also completed by ${ }^{1} \mathrm{H},{ }^{13} \mathrm{C}$, ${ }^{19} \mathrm{~F},{ }^{29} \mathrm{Si}$ and ${ }^{31} \mathrm{P}$ spectra (Fig. S21-S27 $\dagger$ ). Altogether, this data confirmed that dppm adduct 8 activates hydrogen reversibly and is in equilibrium with the dihydride species 11. No semihydrogenation of the triple bonds is observed in this case.

Recording the J-resolved spectrum with ${ }^{31} \mathrm{P}$ decoupling allows extracting the $J_{\mathrm{HRh}}$ coupling constants (Fig. 2c). While the hydride at $\delta^{1} \mathrm{H}=-16.3 \mathrm{ppm}$ appears as a doublet of doublets $\left(J_{\mathrm{HRh}}=20.4,11.8 \mathrm{~Hz}\right)$, the hydride at $\delta^{1} \mathrm{H}=-20.2 \mathrm{ppm}$ appears as a pseudo-triplet $\left(J_{\mathrm{HRh}}=11.8 \mathrm{~Hz}\right)$. The observed ${ }^{2} J_{\mathrm{HH}}$ coupling of $15.4 \mathrm{~Hz}$ is larger than typically found in traditional cis hydrides formed via oxidative addition $\left({ }^{2} J_{\mathrm{HH}}=7.2-9.5 \mathrm{~Hz}\right),{ }^{56}$ suggesting another geometry since higher coupling constants indicate larger angles between the substituents. Overall, these results are consistent with a bridging geometry for the dihydride 11 (Fig. 2a). Assignment of $\mathrm{H}_{\mathrm{a}}$ cis to the intermetallic bond is based on the observation of a remarkable long-range ${ }^{4} J_{\mathrm{HH}}$ coupling of $\mathrm{H}_{\mathrm{a}}$ to a $\mathrm{CH}_{2}$ proton $\left({ }^{4} \mathrm{~J}_{\mathrm{HH}}=5.8 \mathrm{~Hz}\right.$, highlighted red in Fig. 2a and b). Unfortunately, recording a J-resolved spectrum with ${ }^{103} \mathrm{Rh}$ decoupling was not successful due to the large difference in the chemical shift, and it was not possible to eliminate the $J_{\mathrm{HRh}}$ couplings from both metal centers at once. Therefore, the $J_{\mathrm{HP}}$ coupling constant could not be accessed with this approach. However, the ${ }^{1} \mathrm{H}^{3}{ }^{31} \mathrm{P}$ coupling constants could be extracted by fitting the observed PHIP signals (Fig. 2d and e). The PHIP spectrum in Fig. 2e was recorded with a ${ }^{31} \mathrm{P}$ decoupling, which selectively eliminates only ${ }^{31} \mathrm{P}$ couplings arising from the dppm moiety. This allows distinguishing coupling constants between the hydrides and dppm/trop phosphorous 
centers. In addition, PHIP experiments allowed to determine the sign of the ${ }^{2} J_{\mathrm{HH}}$ coupling constant between the two hydrides which is negative ${ }^{2} J_{\mathrm{HH}}=-15.4 \mathrm{~Hz}$.

The proton $\mathrm{H}_{\mathrm{a}}$ shows an ${ }^{2} J_{\mathrm{HP}}$ coupling to the dppm ${ }^{31} \mathrm{P}$ center of ${ }^{2} J_{\mathrm{HP}}=13$ and $6 \mathrm{~Hz}$, indicating a cis ${ }^{2} J_{\mathrm{HP}}$ coupling. ${ }^{56}$ The second hydrogen atom $\mathrm{H}_{\mathrm{b}}$ is likely close to the cis position of the trop phosphine center, as suggested by the couplings of ${ }^{2} J_{\mathrm{HP}}=$ 24 and $18 \mathrm{~Hz}$. The coupling to the second dppm phosphorous center is substantially smaller $\left(J_{\mathrm{HP}}=4 \mathrm{~Hz}\right)$. However, the large $J_{\mathrm{HH}}$ coupling constant as well as the similar coupling constants to both Rh centers (resulting in the pseudo-triplet in Fig. $2 \mathrm{~b}$ ) are consistent with an interaction with the second Rh center. This assignment allows reporting a cis coupling constant of ${ }^{2} J_{\mathrm{HRh}}=$ 11.8 Hz. This indicates that the close $\mathrm{Rh}-\mathrm{Rh}$ contact is preserved after the addition of dihydrogen. Having assigned $\mathrm{H}_{\mathrm{a}}$ as the terminal hydride, while $\mathrm{H}_{\mathrm{b}}$ interacts with the two $\mathrm{Rh}$ centers unsymmetrically, the $\mathrm{Rh}-\mathrm{Rh}$ core can be described either as a $\mathrm{Rh}$ (II)- $\mathrm{Rh}$ (II) center or a $\mathrm{Rh}(\mathrm{I}) \rightarrow \mathrm{Rh}$ (III) polarized bond, due to the bridging nature of $\mathrm{H}_{\mathrm{b}}$. Both descriptions imply a close $\mathrm{Rh}-\mathrm{Rh}$ contact. We tested if this hydride reactivity could also be observed with other ligands and subjected tricyclohexylphosphine, diphenylphosphine oxide and triazabicyclodecene ligands to conditions of the in situ PHIP experiments demonstrating that only the dppm ligand leads to the hydride species. However, all PHIP experiments with the added ligand except triazabicyclodecene showed the hyperpolarized signals of methylene $\mathrm{CH}_{2}$ protons with very similar chemical shifts and coupling constants as observed for 9. In addition, a partially negative lineshape signal for the orthohydrogen was observed for all ligands, suggesting that hydrogen activation is reversible (Fig. S31-S33†).

DFT calculations ( $\omega$ B97X-D/def2-SVP) support the proposed reversible hydrogen activation of the monomeric triflate complex 8 leading to the dihydride $\mathbf{1 1}$ (Scheme 3). From the computed 8-SM intermediate, two $\mathrm{H}_{2}$ adducts can be formed: with the $\mathrm{H}_{2}$ molecule coordinated cis $\left(\mathbf{8}-\mathbf{H}_{\mathbf{2}}\right)$ or trans $\left(\mathbf{8} \mathbf{a}-\mathbf{H}_{2}\right)$ to Rh1 (Scheme 3). Both complexes can undergo oxidative addition steps via activated complexes which are located at energetically low lying transition states ([TS1] $]^{\ddagger}: \Delta G=$ $11.4 \mathrm{kcal} \mathrm{mol}^{-1}$; [TS2 $]^{\sharp}: \Delta G=7.1 \mathrm{kcal} \mathrm{mol}^{-1}$ ), leading to dihydrides 8a-HH $\mathbf{H H}_{\mathbf{o x}}$ and 11- $\mathbf{H} \mathbf{H}_{\mathbf{o x}}$, respectively. With the exception of 11-MeCN, all intermediates are relatively close in energy and are expected to be accessible from 8-SM at room temperature. Since 11-HH $\mathbf{H}_{\mathbf{o x}}$ has an open coordination site trans to Rh1, binding of one acetonitrile ligand occurs giving a more stable species 11MeCN $\left(\Delta G=-19.8 \mathrm{kcal} \mathrm{mol}^{-1}\right)$ with a distorted octahedral coordination environment around $\mathrm{Rh} 2$, as expected for $\mathrm{Rh}(\mathrm{III}) \mathrm{d}^{6}$ complexes. The energy of the coordinatively saturated 11-MeCN is only slightly higher than that of 8-MeCN $(\Delta G=-12.3$ and $-16.8 \mathrm{kcal} \mathrm{mol}^{-1}$, respectively). These two complexes are therefore expected to slowly interconvert and be observable in solution, which is indeed supported by NMR spectroscopy. We note that $\Delta \Delta G$ values from DFT calculations and variable temperature NMR measurements obtained from a Van't Hoff plot (Fig. S16†) are in reasonable agreement $(\Delta \Delta G=4.5$ and $1.1 \mathrm{kcal} \mathrm{mol}^{-1}$, respectively). It is of note that since the

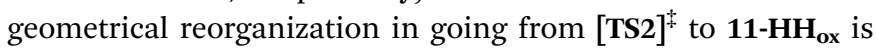

only minimal, the barrier for this step is very low and we attribute the small positive energy difference between $\mathbf{1 1}-\mathbf{H H}_{\mathbf{o x}}$ and [TS2] to the numerical inaccuracy of the applied DFT method. In addition, we note that the bimetallic hydrogen activation pathway involving a four-membered $\mathrm{M}_{2} \mathrm{H}_{2}$ transition state was not considered because this reaction is symmetry forbidden. ${ }^{57}$

Interestingly, a bridging hydride resembling that in $\mathbf{1 1}$ has been proposed and calculated in both rhodium-based homogeneous bimetallic ${ }^{28}$ and heterogeneous systems. ${ }^{26}$ This observation further underlines the utility of low valent homobimetallic complexes with ligands containing alkene and alkyne binding sites in understanding elementary steps in heterogeneous catalysts which are deposited on carbon support materials.

Bimetallic dirhodium complexes 7-9 and the monometallic catalyst $\mathbf{1 2}$ were then tested as catalysts for the semihydrogenation of phenylacetylene $\left(5 \%\right.$ catalyst loading, $25{ }^{\circ} \mathrm{C}$, Fig. 3, for details see ESI†). No activation period was observed (Fig. S41†). The dppm adduct 8 showed highest performance with a selectivity for styrene of $96 \%$ at $78 \%$ conversion and $k_{\text {obs }}$ around 3-5 times higher than those for monomeric triflate complex 7 and carbene complex 9 (Table 3, entries 1-3). The similar rates $k_{\text {obs }}$ observed with 7 and 9 indicate that the in situ hydrogenation of 7 to 9 takes place under the catalytic conditions and leads to the same active species, consistent with the presence of the hyperpolarized $\mathrm{CH}_{2}$ signals characteristic for $\mathbf{9}$ in these catalytic reactions according to in situ PHIP NMR (Fig. S42†). Importantly, PHIP results also show that the dihydride species $\mathbf{1 1}$ form from $\mathbf{8}$ under catalytic conditions (Fig. S43†).

Remarkably, the monometallic catalyst $\mathbf{1 2}$ converts phenylacetylene significantly slower than all tested bimetallic complexes, with a rate of $k_{\text {obs }}=9.5 \times 10^{-3} \mathrm{~h}^{-1}$ (Table 3, entry 4 ). We speculate that the second metal serves as an electron reservoir which helps to avoid the formation of an inert trop$\mathrm{Rh}(\mathrm{III}) \mathrm{d}^{6}$ species $^{58}$ formed by oxidative addition of dihydrogen. PHIP experiment performed under catalytic conditions with the ddpm adduct 8 indicates a pairwise hydrogen transfer to phenylacetylene forming styrene, i.e. hydrogen is activated by 8 to give dihydride 11, followed by the transfer of the two hydrides to the same substrate molecule (Fig. S43†).

\section{Conclusions}

The $\{(\mathrm{TMS}) \mathrm{C} \equiv \mathrm{C}\}{ }_{2}$ tropPPh $_{2}$ molecule with one phosphane, one alkene, and two alkyne donor sites was designed to allow the synthesis of a new family of low-valent homobimetallic $\mathrm{Rh}(\mathrm{I})-$ $\mathrm{Rh}(\mathrm{I})$ complexes. The reactivity of these complexes provides insight into possible metal-metal cooperation in hydrogen activation reactions. The unique ligand environment of the $\mathrm{Rh} 2$ site in $\{(\mathrm{TMS}) \mathrm{C} \equiv \mathrm{C}\}{ }_{2}$ tropPPh ${ }_{2}$ complexes makes this ligand an interesting model for the interface between metal clusters and particles and a carbon support material as found in $\mathrm{Rh} / \mathrm{C}$ heterogeneous catalysts. Two distinct modes of intramolecular hydrogenation of the ligand were identified leading to a bridging carbene or an olefin ligand. When stabilized by a dppm ligand, an intermediate hydride species could be 
characterized by advanced NMR methods which show that this species has a structure with a bridging and a terminal hydride ligand.

\section{Conflicts of interest}

The authors declare no conflicts of interest.

\section{Acknowledgements}

We gratefully acknowledge financial support of Swiss National Science Foundation. I. V. K. acknowledges the grant from the Russian Science Foundation (19-13-00172) for the support of hydrogenation experiments with parahydrogen. K. V. K thanks SB RAS integrated research program (\# 0333-2018-0006/II.1.13) for parahydrogen activation studies and Ministry of Science and Higher Education of the RF (AAAA-A16-116121510087-5) for access to NMR equipment. A. F. thanks the Holcim Stiftung for the Habilitation fellowship.

\section{Notes and references}

1 H. Vahrenkamp, Angew. Chem., Int. Ed., 1978, 17, 379-392. 2 M. P. Doyle, Chem. Rev., 1986, 86, 919-939.

3 H. M. L. Davies and D. Morton, Chem. Soc. Rev., 2011, 40, 1857-1869.

4 H. M. L. Davies and J. R. Manning, Nature, 2008, 451, 417. 5 J. Adams and D. M. Spero, Tetrahedron, 1991, 47, 1765-1808. 6 J. F. Berry and C. M. Thomas, Dalton Trans., 2017, 46, 54725473.

7 Y.-Y. Zhou and C. Uyeda, Angew. Chem., Int. Ed., 2016, 55, 3171-3175.

8 J. Ye, R. C. Cammarota, J. Xie, M. V. Vollmer, D. G. Truhlar, C. J. Cramer, C. C. Lu and L. Gagliardi, ACS Catal., 2018, 8, 4955-4968.

9 R. B. Siedschlag, V. Bernales, K. D. Vogiatzis, N. Planas, L. J. Clouston, E. Bill, L. Gagliardi and C. C. Lu, J. Am. Chem. Soc., 2015, 137, 4638-4641.

10 M. K. Karunananda and N. P. Mankad, ACS Catal., 2017, 7, 6110-6119.

11 M. E. Broussard, B. Juma, S. G. Train, W.-J. Peng, S. A. Laneman and G. G. Stanley, Science, 1993, 260, 17841788.

12 D. R. Pye and N. P. Mankad, Chem. Sci., 2017, 8, 1705-1718.

13 M.-E. Moret, in Higher Oxidation State Organopalladium and Platinum Chemistry, ed. A. J. Canty, Springer Berlin Heidelberg, Berlin, Heidelberg, 2011, pp. 157-184.

14 R. J. Oeschger, D. H. Ringger and P. Chen, Organometallics, 2015, 34, 3888-3892.

15 D. Serra, M.-E. Moret and P. Chen, J. Am. Chem. Soc., 2011, 133, 8914-8926.

16 R. J. Oeschger and P. Chen, J. Am. Chem. Soc., 2017, 139, 1069-1072.

17 R. J. Oeschger and P. Chen, Organometallics, 2017, 36, 14651468.

18 J. P. Krogman and C. M. Thomas, Chem. Commun., 2014, 50, 5115-5127.
19 R. C. Cammarota, L. J. Clouston and C. C. Lu, Coord. Chem. Rev., 2017, 334, 100-111.

20 D. C. Powers and T. Ritter, Acc. Chem. Res., 2012, 45, 840-850. 21 P. M. Maitlis, H. C. Long, R. Quyoum, M. L. Turner and Z.-Q. Wang, Chem. Commun., 1996, 1-8.

22 P. M. Maitlis, J. Organomet. Chem., 2004, 689, 4366-4374.

23 P. M. Maitlis and V. Zanotti, Catal. Lett., 2008, 122, 80-83.

24 C. H. Bartholomew and R. J. Farrauto, Hydrogenation and Dehydrogenation of Organic Compounds, John Wiley and Sons, Hoboken, NJ, 2nd edn, 2005.

25 P. Serna and B. C. Gates, Acc. Chem. Res., 2014, 47, 26122620.

26 A. Dutta and P. Mondal, J. Phys. Chem. C, 2018, 122, 1692516939.

27 A. S. Weller and J. S. McIndoe, Eur. J. Inorg. Chem., 2007, 4411-4423.

28 F. W. Patureau, S. de Boer, M. Kuil, J. Meeuwissen, P.-A. R. Breuil, M. A. Siegler, A. L. Spek, A. J. Sandee, B. de Bruin and J. N. H. Reek, J. Am. Chem. Soc., 2009, 131, 6683-6685.

29 A. J. Esswein, A. S. Veige and D. G. Nocera, J. Am. Chem. Soc., 2005, 127, 16641-16651.

30 R. C. Matthews, D. K. Howell, W.-J. Peng, S. G. Train, W. D. Treleaven and G. G. Stanley, Angew. Chem., Int. Ed. Engl., 1996, 35, 2253-2256.

31 J. F. Berry and C. C. Lu, Inorg. Chem., 2017, 56, 7577-7581. 32 I. G. Powers and C. Uyeda, ACS Catal., 2017, 7, 936-958.

33 J. Thomaier, S. Boulmaâz, H. Schönberg, H. Rüegger, A. Currao, H. Grützmacher, H. Hillebrecht and H. Pritzkow, New J. Chem., 1998, 22, 947-958.

34 L. Bettucci, C. Bianchini, W. Oberhauser, M. Vogt and H. Grützmacher, Dalton Trans., 2010, 39, 6509-6517.

35 H. Schönberg, S. Boulmaâz, M. Wörle, L. Liesum, A. Schweiger and H. Grützmacher, Angew. Chem., Int. Ed., 1998, 37, 1423-1426.

36 F. Breher, H. Rüegger, M. Mlakar, M. Rudolph, S. Deblon, H. Schönberg, S. Boulmaâz, J. Thomaier and H. Grützmacher, Chem.-Eur. J., 2004, 10, 641-653.

37 S. Boulmaâz, S. Loss, H. Schönberg, S. Deblon, M. Wörle, R. Nesper, H. Grützmacher and M. Mlakar, Chem. Commun., 1998, 2623-2624.

38 A. S. Kiryutin, G. Sauer, A. V. Yurkovskaya, H.-H. Limbach, K. L. Ivanov and G. Buntkowsky, J. Phys. Chem. C, 2017, 121, 9879-9888.

39 R. A. Green, R. W. Adams, S. B. Duckett, R. E. Mewis, D. C. Williamson and G. G. R. Green, Prog. Nucl. Magn. Reson. Spectrosc., 2012, 67, 1-48.

40 T. C. Eisenschmid, R. U. Kirss, P. P. Deutsch, S. I. Hommeltoft, R. Eisenberg, J. Bargon, R. G. Lawler and A. L. Balch, J. Am. Chem. Soc., 1987, 109, 8089-8091.

41 C. R. Bowers and D. P. Weitekamp, J. Am. Chem. Soc., 1987, 109, 5541-5542.

42 S. B. Duckett and N. J. Wood, Coord. Chem. Rev., 2008, 252, 2278-2291.

43 B. Le Bourdonnec and R. E. Dolle, US Pat., 20080275131, 2008. 
44 A. W. Addison, T. N. Rao, J. Reedijk, J. van Rijn and G. C. Verschoor, J. Chem. Soc., Dalton Trans., 1984, 13491356.

45 P. K. Sajith and C. H. Suresh, Dalton Trans., 2010, 39, 815822.

46 G. Banditelli and A. L. Bandini, Organometallics, 2006, 25, 1578-1582.

47 W. A. Herrmann, Angew. Chem., Int. Ed., 1978, 17, 800-812.

48 C. A. Laskowski and G. L. Hillhouse, Chem. Sci., 2011, 2, 321325.

49 A. Pidcock, R. E. Richards and L. M. Venanzi, J. Chem. Soc. A, 1966, 1707-1710.

50 W. A. Herrmann, J. Plank, D. Riedel, M. L. Ziegler, K. Weidenhammer, E. Guggolz and B. Balbach, J. Am. Chem. Soc., 1981, 103, 63-75.

51 P. B. Graham, M. D. Rausch, K. Taeschler and W. Von Philipsborn, Organometallics, 1991, 10, 3049-3052.
52 O. G. Salnikov, H.-J. Liu, A. Fedorov, D. B. Burueva, K. V. Kovtunov, C. Copéret and I. V. Koptyug, Chem. Sci., 2017, 8, 2426-2430.

53 K. V. Kovtunov, D. A. Barskiy, R. V. Shchepin, A. M. Coffey, K. W. Waddell, I. V. Koptyug and E. Y. Chekmenev, Anal. Chem., 2014, 86, 6192-6196.

54 V. V. Zhivonitko, V.-V. Telkki, K. Chernichenko, T. Repo, M. Leskelä, V. Sumerin and I. V. Koptyug, J. Am. Chem. Soc., 2014, 136, 598-601.

55 D. A. Barskiy, K. V. Kovtunov, I. V. Koptyug, P. He, K. A. Groome, Q. A. Best, F. Shi, B. M. Goodson, R. V. Shchepin, A. M. Coffey, K. W. Waddell and E. Y. Chekmenev, J. Am. Chem. Soc., 2014, 136, 3322-3325. 56 A. Koch and J. Bargon, Inorg. Chem., 2001, 40, 533-539.

57 G. Trinquier and R. Hoffmann, Organometallics, 1984, 3, 370-380.

58 F. F. Puschmann, H. Grützmacher and B. d. Bruin, J. Am. Chem. Soc., 2010, 132, 73-75. 